\title{
Endovascular radiofrequency renal denervation in resistant hypertension: a single center experience
}

\author{
Aurelio Negro, ${ }^{1}$ Antonio Manari, ${ }^{2}$ Rosaria Santi, ${ }^{1}$ Chiara Grasselli, ${ }^{1}$ Simona Davoli, ${ }^{1}$ Gianluca Pignatelli, ${ }^{2}$ \\ Mila Menozzi, ${ }^{2}$ Franco Perazzoli ${ }^{1}$ \\ ${ }^{1}$ Seconda Medicina Interna, AO S. Maria Nuova - IRCCS; ${ }^{2}$ Cardiologia Interventistica, AO S. Maria Nuova - IRCCS, Reggio \\ Emilia, Italy
}

\begin{abstract}
Eight patients with office blood pressure $>140 / 90 \mathrm{mmHg}$, despite being treated with at least three antihypertensive drugs, underwent catheter-based renal denervation. Secondary hypertension was excluded in all patients. Every patient underwent follow-up at 30 days, and then every 3 months. At 6 and 12 months the median value of systolic clinic blood pressure decreased from $161 \mathrm{mmHg}\left(25^{\text {th }}-75^{\text {th }}\right.$ percentiles: $\left.158-191 \mathrm{mmHg}\right)$ at baseline to $144 \mathrm{mmHg}\left(25^{\text {th }}-75^{\text {th }}\right.$ percentiles: $\left.136-153 \mathrm{mmHg}\right)$ at follow up $(\mathrm{P}=0.012)$, and the median value of diastolic clinic blood pressure decreased from $102 \mathrm{mmHg}\left(25^{\text {th }}-75^{\text {th }}\right.$ percentiles: $94-$ $122 \mathrm{mmHg})$ at baseline to $90 \mathrm{mmHg}\left(25^{\text {th }}-75^{\text {th }}\right.$ percentiles: $\left.78-99 \mathrm{mmHg}\right)$ at follow-up $(\mathrm{P}=0.012)$. The number of medications decreased from 5 (range, 2-8) at baseline to 3.3 (range, 0-6) at follow up. There was a significant decrease of left ventricular mass index from a median of $160 \mathrm{~g} / \mathrm{m}^{2}\left(25^{\text {th }}-75^{\text {th }}\right.$ percentiles: $\left.147-151 \mathrm{~g} / \mathrm{m}^{2}\right)$ at baseline to $126 \mathrm{~g} / \mathrm{m}^{2}\left(25^{\text {th }}-75^{\text {th }}\right.$ percentiles 107 $\left.151 \mathrm{~g} / \mathrm{m}^{2}\right)$ at follow-up $(\mathrm{P}=0.043)$ was detected. The renal function, and metabolic and neurohumoral parameters, did not change significantly. No complications were observed.
\end{abstract}

\section{Introduction}

Hypertension is a leading risk factor influencing the global burden of cardiovascular disease. In spite of the fact that measures such as lifestyle changes and pharmacological treatment reduce blood pressure (BP) and cardiovascular complications in hypertensive patients, worldwide the treatment of hypertension remains suboptimal with consequent inadequately controlled blood pressure in many patients. ${ }^{1,2}$ Of note, patients in whom target BP values are not reached despite prescription of triple therapy, including a diuretic at maximum tolerated dose, are defined as having resistant hypertension, according to the current guide-

Correspondence: Aurelio Negro, viale Risorgimento 80, 42100 Reggio Emilia, Italy.

Tel.: +39.0522.296866 - Fax: +39.0522.295896.

E-mail: negro.aurelio@asmn.re.it

Key words: resistant hypertension, radiofrequency renal denervation, catheter-based renal denervation.

Received for publication: 11 April 2013.

Revision received: not required.

Accepted for publication: 7 May 2013.

This work is licensed under a Creative Commons Attribution NonCommercial 3.0 License (CC BY-NC 3.0).

C Copyright A. Negro et al., 2014

Licensee PAGEPress, Italy

Italian Journal of Medicine 2014; 8:29-34

doi:10.4081/itjm.2013.174 lines of the European Society of Hypertension. ${ }^{1}$ From 5 to $30 \%$ of cases have resistant hypertension. ${ }^{3-5} \mathrm{~Pa}-$ tients with resistant hypertension are exposed prematurely to target organ dysfunction and to early occurrence of cardiovascular, cerebrovascular and renal complications, leading to increased mortality. ${ }^{6}$ The role of the renal sympathetic nervous system in BP regulation is complex and the system is considered as one among multiple systems involved in the initiation, progression and persistence of hypertension. In particular, increased sympathetic activity has been shown to characterize resistant hypertension. ${ }^{7-10}$ Historically, radical surgical methods for sympathetic denervation have been successful in lowering blood pressure in severely hypertensive patients. However, these methods of sympathectomy were associated with high perioperative morbidity and serious long-term complications. ${ }^{11}$ Catheter-based renal sympathetic denervation by radiofrequency $(\mathrm{RDN})$ is a new method that can disrupt both the efferent and afferent sympathetic nervous fibers that follow the renal artery to the kidney within the adventitia. ${ }^{10}$ In the recent, first study in humans, RDN was associated with significant and persistent reductions in systolic and diastolic blood pressure beyond those produced by medical therapy. ${ }^{12}$ These findings were subsequently confirmed by the Symplicity HTN-2 Trial, the first randomized, controlled study using this technique of renal denervation. ${ }^{13}$

Here we report the results of our single center experience with percutaneous RDN, applied to patients in daily clinical practice affected by resistant hypertension. Our aim was to assess the safety and long-term blood pressure-lowering effectiveness of therapeutic renal denervation in highly selected patients. 


\section{Materials and Methods}

\section{Patients}

Patients were judged eligible for RDN if they had clinic BP $>140 / 90 \mathrm{mmHg}$ despite being treated with at least three antihypertensive drugs, or a controlled $\mathrm{BP}$ with four or more antihypertensive drugs, or confirmed and sustained intolerance to medications. BP measurements were performed in the morning by a member of the medical staff, in a seated position with three consecutive readings after a 10-min rest; the average of these three readings was recorded. The BP was checked before the intervention and at follow-up for each patient. Twenty-four hour ambulatory blood pressure monitoring (ABPM) was initially performed, mainly to exclude a white-coat effect. The renal artery anatomy was evaluated by computed tomography or magnetic nuclear resonance angiography and considered appropriate for treatment in the case of a vessel diameter of $>4 \mathrm{~mm}$ and length $>20 \mathrm{~mm}$ without any significant renal artery stenosis or anatomic abnormalities. Secondary forms of hypertension, such as primary aldosteronism, renovascular hypertension, pheochromocytoma, renal disease, and Cushing's disease were carefully excluded. Renal function was determined and levels of neurohumoral factors such as glucose, insulin, renin, aldosterone, ACTH, cortisol and catecholamines were measured. Transthoracic echocardiography, to assessed left ventricular hypertrophy, was performed and interpreted by two experienced echocardiographers at baseline and at follow-up for each patient. The left ventricular mass (LVM) was calculated using the Devereux formula; LVM was indexed to body surface area. ${ }^{14}$ All patients had normal ejection fractions on echocardiography and no clinical signs or symptoms of heart failure.

All patients provided written and informed consent.

\section{Procedure}

All RDN procedures were performed by a cardiologist expert in endovascular procedures. The femoral artery was accessed with the standard endovascular technique using a $6 \mathrm{~F}$ sheath. A selective bilateral renal angiogram was performed with a standard JR catheter before and after the procedure. The treatment catheter (Symplicity by Ardian Inc, Palo Alto, CA, USA) was inserted into each renal artery and radiofrequency ablations of 8 Watts or less, lasting up to 2 minutes each, were applied separated both longitudinally and rotationally, to obtain up to six ablations. During ablation, the catheter system monitored tip temperature and impedance, altering radiofrequency energy delivery in response to a predetermined algorithm. Conscious sedation, using intravenous narcotics and anxiolytics was, commonly induced to prevent and manage expected visceral pain. A dose of 5000 IU of unfractionated heparin IV was administered before the procedure. Repeated intra-arterial boluses of nitroglycerin were given before and after the treatment.

\section{Follow-up}

All patients underwent follow-up at 30 days and then every 3 months. The follow-up consisted of clinical examination, office BP measurements, besides ABPM, biochemical analysis, renal duplex sonography, and transthoracic echocardiography performed at 6 and 12 months. Routine angiographic control was not planned as part of the follow-up. The median follow-up was 9 months (range, 2-22 months).

\section{Statistical analysis}

Data are reported as medians and percentages. Comparisons between baseline and follow-up data after the RDN procedure were analyzed by Wilcoxon's signed ranks test. All computations were performed using SPSS/PC + . A P value $<0.05$ was taken to denote a statistically significant difference.

\section{Results}

\section{Patients' characteristics}

We treated eight patients in this open-label, singlecenter series. The baseline characteristics of the subjects, including their demographics and background medication, are listed in Table 1. Patients were middleaged with a median age of 47.5 years $\left(25^{\text {th }}-75^{\text {th }}\right.$ percentiles: 43-63.5), mostly male (75\%), with a median body mass index of $26.9 \mathrm{~kg} / \mathrm{m}^{2}\left(25^{\text {th }}-75^{\text {th }}\right.$ percentiles: $24.0-30.7 \mathrm{~kg} / \mathrm{m}^{2}$ ), and long-lasting hypertension (median 9 years; $25^{\text {th }}-75^{\text {th }}$ percentiles: $3.2-13.7$ years). Type 2 diabetes mellitus was diagnosed in two patients $(25 \%)$. The baseline median clinic systolic and diastolic BP were $161 \mathrm{mmHg}\left(25^{\text {th }}-75^{\text {th }}\right.$ percentiles: $158-191$ $\mathrm{mmHg})$, and $102 \mathrm{mmHg}\left(25^{\text {th }}-75^{\text {th }}\right.$ percentiles: $94-122$ $\mathrm{mmHg}$ ), respectively, despite treatment with 5 (range, 2-8) antihypertensive drugs. The ABPM, performed in six out of eight patients, confirmed the poor control of hypertension with median systolic and diastolic BP values of $160 \mathrm{mmHg}\left(25^{\text {th }}-75^{\text {th }}\right.$ percentiles: $153-181$ $\mathrm{mmHg})$, and $93 \mathrm{mmHg}\left(25^{\text {th }}-75^{\text {th }}\right.$ percentiles: $93-115$ $\mathrm{mmHg}$ ), respectively. All classes of antihypertensive agents were used; some patients showed occasional intolerance to several antihypertensive agents.

\section{Characteristics of the procedures}

The median time from first to last radiofrequency energy delivery was $40 \mathrm{~min}$, with an average of five ablations in each renal artery. There were no device malfunctions. Excessive drop in systolic blood pressure was managed by saline infusion. Post-procedural angiograms did not show endovascular damage, except for the presence of lumen irregularities at any treatment site, and there were no peri-procedural complications at access sites.

\section{Follow-up}

No patients reported symptomatic orthostatic hypotension after the procedure or abrupt rises of BP or 
serum creatinine changes during the follow-up, so no additional renal angiography was needed. Otherwise, periodic renal ultrasound and Doppler studies showed no hemodynamically significant renal artery stenosis. All patients had significant decreases of BP at a mean of 9 months of follow-up. The median value of systolic clinic BP decreased from $161 \mathrm{mmHg}$ at baseline to $144 \mathrm{mmHg}(\mathrm{P}=0.012)$, while the median value of the diastolic clinic BP decreased from $102 \mathrm{mmHg}$ at baseline to $90 \mathrm{mmHg}$ at follow-up $(\mathrm{P}=0.012)$ (Figure $1 \mathrm{~A}$ and $\mathrm{B})$. The ABPM showed similar reductions in systolic and diastolic BP (15\% and $14 \%$, respectively; $\mathrm{P}=0.018$ ) (Figure $2 \mathrm{~A}$ and $\mathrm{B}$ ). No significant changes in the resting heart rate were observed (median preprocedure $73 \mathrm{bpm}$, median post-procedure $71 \mathrm{bpm}$; $\mathrm{P}=$ n.s.). The number of medications changed from a median of 5 at baseline to 3.3 (range, $0-6$ ) in the follow-up. Likewise, all patients had a marked reduction in LVM reduction so the median value decreased from $160 \mathrm{~g} / \mathrm{m}^{2}\left(147-151 \mathrm{~g} / \mathrm{m}^{2}\right)$ at baseline to $121 \mathrm{~g} / \mathrm{m}^{2}(107-$ $\left.151 \mathrm{~g} / \mathrm{m}^{2}\right)$ at follow-up $(\mathrm{P}=0.043)$ (Figure 3). Significant changes were not observed in renal function, metabolic parameters or neurohumoral parameters (Table 2), apart from plasma aldosterone and adrenaline levels. However, no improvement in parameters of glucose metabolism, such as the HOMA index, was observed (Figure 4).

Table 1. Baseline characteristics of the patients $(\mathrm{N}=8)$.

\begin{tabular}{lc}
\hline Characteristics & No. \\
\hline Age, years & $47.5(43-63.5)$ \\
Sex, male & $6(75 \%)$ \\
Race, Caucasian & $8(100 \%)$ \\
Weight, kg & $86(70-115)$ \\
Height, cm & $175(166-190)$ \\
Body mass index & $(24.0-30.7)$ \\
\hline Medical history & No. \\
\hline CAD & None $(0 \%)$ \\
CVA/TIA & $1(12.5 \%)$ \\
Diabetes & $2(25 \%)$ \\
Chronic kidney disease & None $(0 \%)$ \\
Heart rate, bpm & $73(65-80)$ \\
Office SBP, mmHg & $161.0(158.5-191.5)$ \\
Office DBP, mmHg & $102.0(94.2-122.0)$ \\
Mean ABPM SBP, mmHg & $161.2(141-186)$ \\
Mean ABPM DBP (mmHg) & $98.2(80-116)$ \\
Number of antihypertensive drugs & $4.9(2-8)$ \\
ACE inhibitor or ARB & $8(100 \%)$ \\
$\beta$ blockers & $6(75 \%)$ \\
Calcium-channel blockers & $8(100 \%)$ \\
Vasodilators & $6(75 \%)$ \\
Diuretics & $7(85 \%)$ \\
Anti-aldosteronics & $5(65 \%)$ \\
&
\end{tabular}

Data are presented as the median $\left(25^{\text {th }}-75^{\text {th }}\right.$ percentile $)$ and number $(\%)$. $\mathrm{CAD}$, coronary artery disease; CVA/TIA, cardiovascular accident/transitory ischemic attack; bpm, beats per minute; SBP, systolic blood pressure; DBP, diastolic blood pressure; ABPM, 24-h ambulatory blood pressure monitoring; $\mathrm{ACE}$, angiotensin-converting enzyme; ARB, angiotensin II receptor blocker.

\section{Discussion}

The contribution of the sympathetic nervous system to the development and maintenance of hypertension is well recognized, and evidence of increased sympathetic activity has been reported in several studies of essential hypertension. ${ }^{7-9}$ Stimulation of renal sympathetic nerves leads to increased secretion of renin, increased tubular sodium reabsorption, and reduced renal blood flow. ${ }^{10}$ Notably, resistant hypertension has been shown to be characterized by a marked increase of sympathetic activity. ${ }^{11}$ Although the sympathetic contribution to persistently elevated BP in individual patients with resistant hypertension is difficult to determine in clinical practice, the pronounced responses that have been demonstrated after RDN testify to the importance of sympathetic nervous system activity in in many patients with resistant hypertension. $^{12,13}$ Our initial experience with a catheterbased percutaneous RDN confirms the results of the previous major proof-of-principle and randomized studies, ${ }^{12,13}$ subsequently confirmed by others observations as recently reviewed by Schlaich et al. ${ }^{15}$ The decreases of BP that we observed were consistent in all patients and substantially comparable with those achieved in larger studies. The other important observation from our limited experience was the sustained safety. The absence of significant adverse events was documented by the stability of the parameters of renal function and the absence of hemodynamic changes in renal arteries determined by serial evaluations of renal ultrasound and Doppler studies. Whether the satisfying results regarding the $\mathrm{BP}$ control obtained by RDN will pass the test of time in our patients obviously remains to be determined by a longer follow-up. However, a recently published longer follow-up showed a sustained BP reduction of 32/14 mmHg at 24 months after RDN, underscoring the durability of BP control with this treatment. ${ }^{16}$

Resistant hypertension is a medical illness that confers very high risk of stroke, myocardial infarction, renal failure, heart failure, and death. ${ }^{6}$ A recent metaanalysis showed that the incidence of cardiac events was reduced by $22 \%$ after a systolic BP reduction of $10 \mathrm{mmHg}$ or a diastolic BP reduction of $5 \mathrm{mmHg}$; furthermore, the incidence of stroke was reduced by $41 \% .{ }^{17}$ Assuming that $\mathrm{RDN}$ is as effective as pharmacological treatment of hypertension at reducing clinical events, the observed, significant BP reductions in our patients will most likely be highly beneficial. Evidence on the efficacy of RDN on so-called hard cardiovascular endpoints is still lacking. However, there is accumulating evidence on intermediate endpoints, such as left ventricular hypertrophy, which might have important prognostic implications in patients with resistant hypertension. ${ }^{18}$ Furthermore, RDN was recently shown to have a favorable safety profile and beneficial effects on BP in patients with stage 3-4 chronic kidney disease. ${ }^{19}$ A recent European Society of Hypertension position statement claims that patients eligible for RDN should undergo a thorough ex- 
amination to confirm treatment resistance and exclude pseudo-resistance, for instance from a white-coat effect; particularly, persisting high clinic BP in spite of multidrug treatment should be confirmed by 24-h ABPM. ${ }^{20}$ It should be noted that while the primary endpoint of the Symplicity HTN-3 trial, designed as a large prospective and randomized study evaluating the safety and efficacy of RDN for the treatment of resistant hypertension, is the change in office systolic BP, a major secondary efficacy endpoint is the change in average 24-h systolic ABPM from baseline to 6 months. ${ }^{21}$ As in other studies, ${ }^{13}$ in our population satisfactory ABPM were obtained in only six of eight patients. Nevertheless, the available data show a similar, albeit less pronounced, pattern of BP changes at follow-up. The apparent discrepancy between clinic and ambulatory BP levels is well-known and could be, at least partially, attributed to the fact that the higher clinic BP levels are, the larger the discrepancy will be between clinic and ambulatory BP levels. ${ }^{22} \mathrm{We}$ are confident about our clinic BP values because these measurements were performed over a period of sev- eral minutes in the examination room with ideal environmental conditions. Moreover, it should be noted that the drop of ABPM paralleled the reduction of clinic BP in each one of the patients in our series.

One interesting aspect of RDN is its potential to reduce the number of antihypertensive drugs required to control BP. Indeed, it was reported that drug usage was reduced in approximately $20 \%$ of the patients who underwent RDN. ${ }^{23}$ In our case series, despite our policy of modifying therapeutic regimens only if strictly clinically indicated, the median number of antihypertensive drugs decreased from 5 to 3.3. Of note, a 51-year old female patient showed persistent and sustained BP control after RDN in the absence of antihypertensive agents. In addition to the BP-lowering effect, we were able to demonstrate a marked reduction in LVM after RDN, which seemingly paralleled the decrease in BPl. It is well-known that regression of left ventricular hypertrophy improves cardiovascular outcome independently of other risk factors, and thus has been proposed as an intermediate endpoint. ${ }^{24,25}$ However, it is interesting that in the cohort-
A

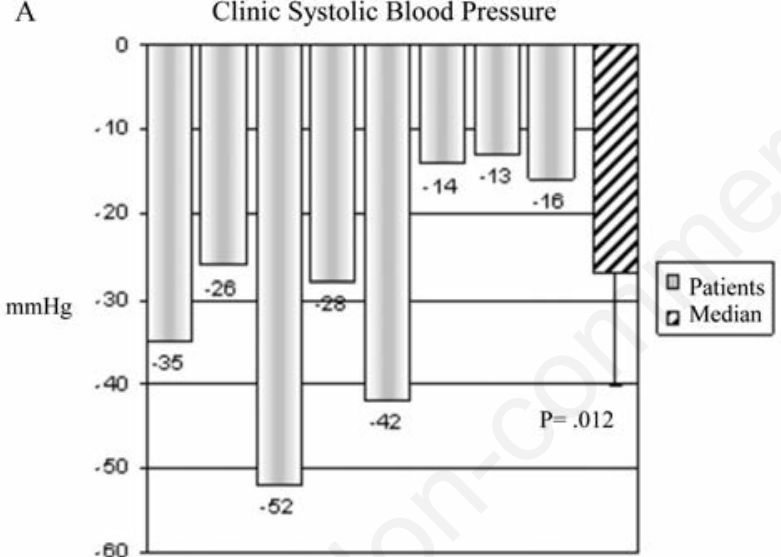

B

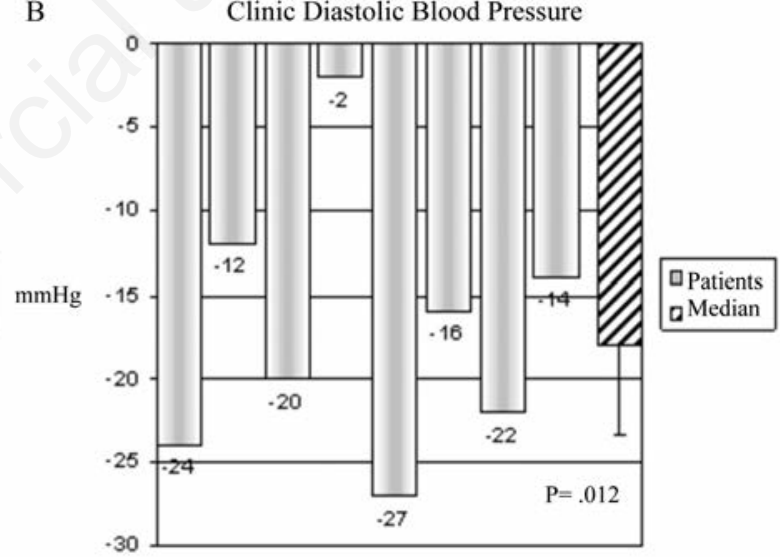

Figure 1. Changes in office (A) systolic and (B) diastolic blood pressure over 9 months of follow-up in each of the eight patients. The $P$ values refer to the change in median blood pressure compared with baseline.

Table 2. Biochemical parameters before and after renal denervation.

\begin{tabular}{lccc}
\hline & Baseline & After RDN & Wilcoxon test (P) \\
\hline Plasma renin activity $(\mathrm{ng} / \mathrm{mL} / \mathrm{h})$ & $3.75(0.35-6.30)$ & $0.95(0.25-16)$ & $\mathrm{n} . \mathrm{s}$. \\
Aldosterone $(\mathrm{pg} / \mathrm{mL})$ & $147.5(60-200)$ & $285(175-490)$ & 0.028 \\
Adrenaline $(\mathrm{pg} / \mathrm{mL})$ & $56.4(15-95.6)$ & $17.3(7.8-57.3)$ & 0.018 \\
Noradrenaline $(\mathrm{pg} / \mathrm{mL})$ & $398.3(126.4-581.8)$ & $313.2(265.3-446.5)$ & n.s. \\
Insuline $(\mathrm{IU} / \mathrm{mL})$ & $20.5(4-31)$ & $19(7-21)$ & $\mathrm{n} . \mathrm{s}$. \\
Glucose $(\mathrm{mg} / \mathrm{dL})$ & $103(96-114)$ & $92(77-104)$ & $\mathrm{n} . \mathrm{s}$. \\
HOMA index & $5.65(0.95-7.8)$ & $4.41(1.59-8.03)$ & $\mathrm{n} . \mathrm{n}$. \\
NT-proBNP $(\mathrm{pg} / \mathrm{mL})$ & $137(50-684)$ & $83(38-806)$ & n.s. \\
Serum creatinine $(\mathrm{mg} / \mathrm{dL})$ & $0.93(0.86-1.09)$ & $0.97(0.85-1-13)$ & n.s.
\end{tabular}

Data are presented as median $\left(25^{\text {th }}-75^{\text {th }}\right.$ percentile). RDN, renal denervation; n.s., not significant; HOMA index, Homeostasis Model Assessment index; NT-proBNP, $\mathrm{N}$-terminal prohormone of brain natriuretic peptide. 
study by Krum et al. ${ }^{12}$ LVM regression occurred in five of six RDN non-responders, possibly due to sympathetic denervation per se.

In our patients there were no significant changes in fasting plasma glucose, HOMA index or PRA, unlike a previously reported decrease in norepinephrine spillover accompanied by halving of plasma renin activity, ${ }^{26}$ and an amelioration of a few glucose metabolism parameters. ${ }^{27} \mathrm{We}$ only observed relevant variations of plasma aldosterone and adrenaline, which are obviously difficult to interpret because of the small size of the case series, and the effects of possible changes in the patients' prescriptions of antihypertensive drugs. The recent report of failure to achieve consistently lower BP and sympathetic activity, measured by muscle sympathetic nerve activity (MSNA), in 12 patients with difficult-to-control hypertension is certainly disturbing. ${ }^{28}$ This study was the first to show that, overall, patients with resistant hypertension did not demonstrate a consistent and clinically relevant $\mathrm{BP}$ reduction since only a few patients responded to this invasive treatment. Moreover, changes in blood pressure and MSNA were not related to each other. However, the authors pointed out that, compared with other clinical trials including carefully selected patients with resistant hypertension, their patients had lower BP and were taking fewer antihypertensive drugs before treatment. Furthermore, in this study there was a large variability in pre-treatment MSNA between patients supporting the observation that the sympathetic contribution to BP is not uniform in all patients with resistant hypertension.

In conclusion, we have reported cases of successful catheter-based RDN in daily clinical practice at a single center in highly selected patients with true, resistant hypertension and at high cardiovascular risk.
A

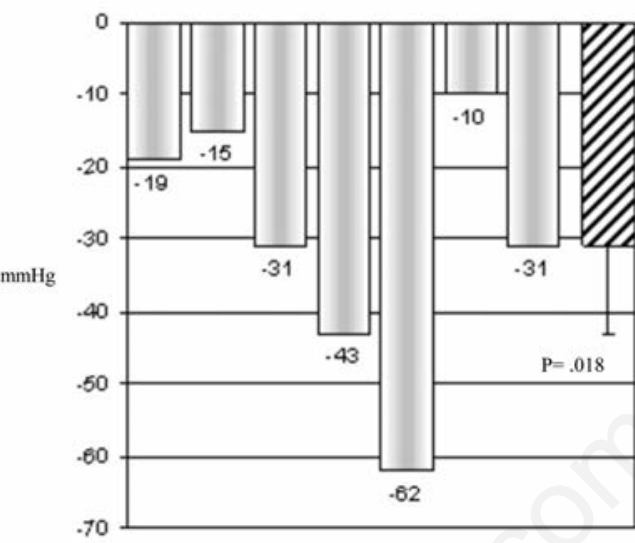

B

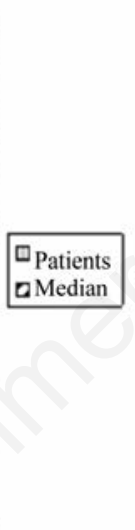

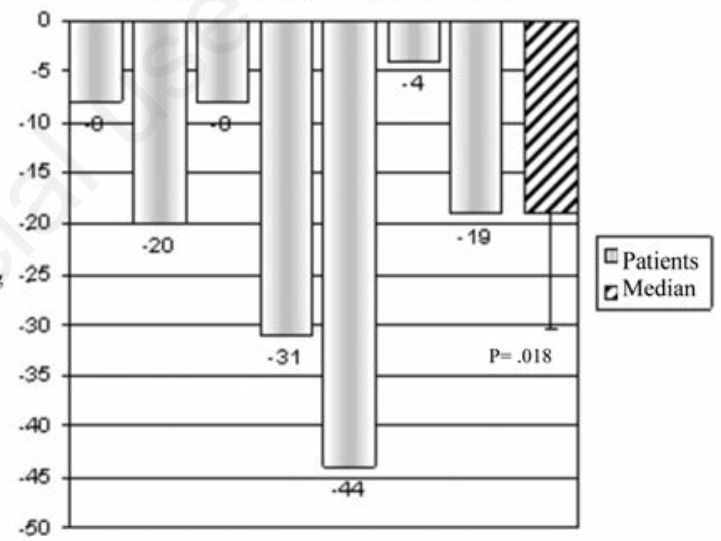

Figure 2. Changes in ambulatory (A) systolic and (B) diastolic blood pressure over 9 months of follow-up. The $P$ values refer to the change in median blood pressure compared with baseline. ABPM, ambulatory blood pressure monitoring.

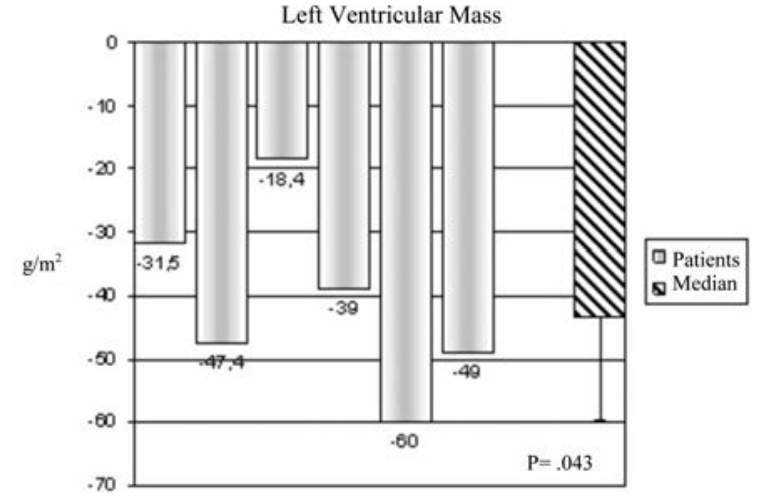

Figure 3. Changes in left ventricular mass over 9 months of follow-up in six of the patients. The $P$ value refers to the change in median left ventricular mass compared with baseline.

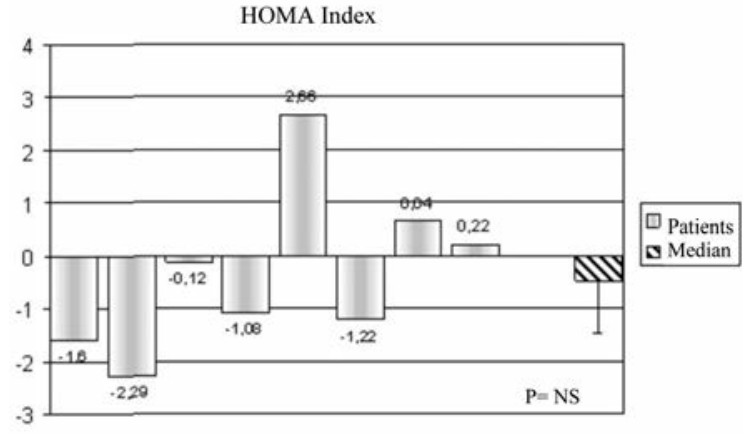

Figure 4. Changes in homeostasis model assessment-insulin resistance (HOMA-IR) over 9 months of follow-up in each of the eight patients. The $P$ value refers to the change in median value from baseline. 
We believe that, at present, in the absence of factors that can predict response and that are easily suitable for use in daily clinical practice, patients should be highly selected for RDN, based on the severity of their BP levels. Our observations contribute to demonstrating that renal nerve ablation may constitute an effective and safe therapeutic choice for the treatment of resistant hypertension. While waiting for more robust and long-term data on safety and efficacy from sufficiently large controlled trials ${ }^{21}$ sound and meditated clinical reasoning should prevail.

\section{References}

1. Mancia G, Laurent S, Agabiti-Rosei E, et al. Reappraisal of European guidelines on hypertension management: a European Society of Hypertension Task Force document. J Hypertens 2009;27:2121-58.

2. Czernichow S, Zanchetti A, Turnbull F, et al. The effect of blood pressure reduction and of different blood pressure-lowering regimens on major cardiovascular events according to baseline blood pressure: meta-analysis of randomized trials. J Hypertens 2011;29:4-16.

3. Persell SD. Prevalence of resistant hypertension in the United States, 2003-2008. Hypertension 2011;57:1076-80.

4. Prugger C, Keil U, Wellmann J, et al. Blood pressure control and knowledge of target blood pressure in coronary patients across Europe: results from the EURO-ASPIRE III survey. J Hypertens 2011;29:1641-8.

5. de la Sierra A, Segura J, Banegas JR, et al. Clinical features of 8295 patients with resistant hypertension classified on the basis of ambulatory blood pressure monitoring. Hypertension 2011;57:898-902.

6. Cuspidi C, Macca G, Sampieri L, et al. High prevalence of cardiac and extracardiac target organ damage in refractory hypertension. J Hypertens 2011;19:2063-70.

7. Tsioufis C, Kordalis A, Flessas D, et al. Pathophysiology of resistant hypertension: the role of sympathetic nervous system. Int J Hypertens 2011;2011:ID642416.

8. Esler M, Lambert G, Jennings G. Regional norepinephrine turnover in human hypertension. Clin Exp Hypertens A 1989;11:75-89.

9. Grassi G, Cattaneo BM, Seravalle G, et al. Baroreflex control of sympathetic nerve activity in essential and secondary hypertension. Hypertension 1998;31:68-72.

10. DiBona GF, Esler M. Translational medicine: the antihypertensive effect of renal denervation. Am J Physiol Regul Integr Comp Physiol 2010;298:R245-R253.

11. Morrissey DM, Brookes VS, Cooke WT. Sympathectomy in the treatment of hypertension: review of 122 cases. Lancet 1953;1:403-8.

12. Krum H, Schlaich M, Whitbourn R, et al. Catheter-based renal sympathetic denervation for resistant hypertension: a multicentre safety and proof-of-principle cohort study. Lancet 2009;373:1275-81.

13. Esler MD, Krum H, Sobotka PA, et al on behalf of the Symplicity HTN-2 Investigators. Renal sympathetic denervation in patients with treatment resistant hypertension (The Symplicity HTN-2 Trial): a randomized controlled trial. Lancet 2010;376:1903-9.
14. Lang RM, Bierig M, Devereux RB, et al. Recommendations for chamber quantification: a report from the American Society of Echocardiography's Guidelines and Standards Committee and the Chamber Quantification Writing Group. J Am Soc Echocardiogr 2005; 18:1440-63.

15. Schlaich MP, Hering D, Sobotka PA, et al. Renal denervation in human hypertension: mechanisms, current findings, and future prospects. Curr Hypertens Rep 2012;14:247-53.

16. Symplicity HTN-1 Investigators 2011. Catheter-based renal sympathetic denervation for resistant hypertension: durability of blood pressure reduction out to 24 months. Hypertension 2011;57:911-7.

17. Law MR, Morris JK, Wald NJ. Use of blood pressure lowering drugs in the prevention of cardiovascular disease: meta-analysis of 147 randomised trials in the context of expectations from prospective epidemiological studies. BMJ 2009;338:b1665.

18. Brandt MC, Mahfoud F, Reda S, et al. Renal sympathetic denervation reduces left ventricular hypertrophy and improves cardiac function in patients with resistant hypertension. J Am Coll Cardiol 2012;59:901-9.

19. Hering D, Mahfoud F, Walton AS, et al. Renal denervation in moderate to severe CKD. J Am Soc Nephrol 2012;23:1250-7.

20. Schmieder RE, Redon J, Grassi G, et al. ESH position paper: renal denervation - an interventional therapy of resistant hypertension. J Hypertens 2012;30:837-41.

21. Kandzari DE, Depak LB, Sobotka PA, et al. Catheterbased renal denervation for resistant hypertension: rationale and design of the SYMPLICITY HTN-3 trial. Clin Cardiol 2012;35:528-35.

22. Bur A, Herkner H, Vlcek M, et al. Classification of blood pressure levels by ambulatory blood pressure in hypertension. Hypertension 2002;40:817-22.

23. Schlaich MP, Krum H, Sobotka PA, Esler MD. Renal denervation and hypertension. Am J Hypertens 2011; 24:635-42.

24. Fagard RH, Celis H, Thijs L, Wouters S. Regression of left ventricular mass by antihypertensive treatment: a meta-analysis of randomized comparative studies. Hypertension 2009;54:1084-91.

25. Pierdomenico SD, Cuc curullo F. Risk reduction after regression of echocardiographic left ventricular hypertrophy in hypertension: a meta-analysis. Am J Hypertens 2012;23:876-81.

26. Schlaich MP, Sobotka PA, Krum H, et al. Renal sympathetic-nerve ablation for uncontrolled hypertension. $\mathrm{N}$ Eng J Med 2009;361:932-4.

27. Witkowski A, Prejibisz A, Florczak E, et al. Effects of renal sympathetic denervation on blood pressure, sleep apnea course, and glycemic control in patients with resistant hypertension and sleep apnea. Hypertension 2011;58:559-65.

28. Brinkmann J, Heusser K, Schmidt BM, et al. Catheterbased renal nerve ablation and centrally generated sympathetic activity in difficult-to-control hypertensive patients. Hypertension 2012;60:1485-90. 